\title{
Analysis of the Parameters of the Ore Restoration Furnaces for Equal Power on the Shelf-Baking and Graphitized Electrodes
}

\author{
Vladimir Kldiashvili, Tamaz Natriashvili, Slava Mebonia and Aleksandre Shermazanashvili \\ R. Dvali Institute of Machine Mechanics, 10 Mindeli str., Tbilisi 0186, Georgia
}

Received: August 03, 2016 / Accepted: August 16, 2016 / Published: December 31, 2016.

\begin{abstract}
Results of calculation of the power indicators of the ore restoration arc furnaces with the set power of 10.5 MVA working on are given as on the self-baking also on the graphitized electrodes. It is established that despite high cost of the graphitized electrodes in comparison with the self-baking electrodes, power parameters much more improve. Besides, the natural power factor increases, melting time decreases and that the most important the furnace turns out compact, convenient for service, building of the graphitized electrodes is carried out for a small period, and also the number of service personnel is reduced. We propose a new design scheme of low-voltage circuit for the arc furnace according to the scheme "a triangle on the electrodes" designed in a three-bifilar version, in which more complete symmetry is gained by means of the crosspieces forming a triangle directly at the electrode arms. In the proposed scheme, the current-carrying tubes that have different polarity are located on the same arm that leads to further reduction in low-voltage circuit inductance. The application of this scheme allows for reducing reactive and active resistances of low-voltage circuits by 2.5-3 times and 15-20\%, respectively, as well as for shortening the heat, reducing specific energy consumption and increasing the installation power factor.
\end{abstract}

Key words: Power indicators, ore restoration, arc furnace, self-baking, graphitized electrode, low-voltage circuit, reactive resistance, bifilar arrangement of tires.

\section{Introduction}

In recent years with rapid rates are developed works on creation and introduction in production of ferroalloy furnaces of low and average power. Certain success in this direction is also achieved in Georgia. In particular, we have developed and introduced the ore restoration closed electric furnace with power $10,500 \mathrm{kV} \cdot \mathrm{A}$ for production of $75 \%$ ferrosilicium on "GTM-Group" LTD (Zestafoni, Argveta). This furnace is designed and constructed on the graphitized electrodes [1-5].

It is known that each ore thermal process of melting generally has three parameters characteristic only for this process:

Corresponding author: Vladimir Kldiashvili, professor, research fields: electrical engineering and electric thermo engineering.
(1) Specific power consumption on product ton;

(2) Specific electric resistance of a bathtub;

(3) Power density in the acting bathtub volume.

These parameters are not strictly constant. They are under influence of quality of the charge, its structure and an expense which define amount of the formed slag and extent of extraction from ores of the leading elements, and also the electric mode of melting. The power of the furnace and a design of a bathtub (open or closed), a way of loading also influence these parameters but in much smaller degree [6].

\section{Basic Part}

For comparison of power indicators we will carry out calculations of the furnaces with the set power of 10.5 MV·A working on self-baking and graphitized electrodes. For such furnaces power $10.5 \mathrm{MV} \cdot \mathrm{A}$ is a 
limit due to the lack of the graphitized electrodes of big diameters. Here we will note that the industry turns out the graphitized electrodes with the nominal diameter no more than $700 \mathrm{~mm}$.

\subsection{The Furnace on the Shelf-Baking Electrode}

We will consider the operating furnace with power 10.5 MV·A for production of $75 \%$ ferrosilicium with the following electrical parameters [7]:

- useful power of the furnace: $P_{u s}=8.49 \mathrm{MW}$;

- working current of the electrode: $I_{e l}=40 \mathrm{kA}$;

- working tension: $\mathrm{U}=156 \mathrm{~V}$;

- diameter of the self-baking electrode: $d_{e l}=900$ $\mathrm{mm}$;

- the internal sizes of the furnace bathtub: diameter is equal to $4,400 \mathrm{~mm}$, the depth: $1,990 \mathrm{~mm}$;

- the scheme of connection of the short network - a triangle on the electrodes where the current supply to electrodes is carried out through the contact cheeks, and electrodes are kept on weight by special devices.

Reactive resistance of the short network of this furnace on phases is respectively equal: for the 1st phase of $0.48 \mathrm{~m} \Omega$; for the $2 \mathrm{nd}$ phase of $0.42 \mathrm{~m} \Omega$; for the $3 \mathrm{rd}$ phase of $0.45 \mathrm{~m} \Omega$. Reactance of all the three phases is equal in total to $1.35 \mathrm{~m} \Omega$ that makes $40.5 \%$ of the general reactance of the system.

For electrodes and a bathtub above-mentioned resistance on phases are equal to $0.43 \mathrm{~m} \Omega$ for each phase that in the sum makes $1.29 \mathrm{~m} \Omega$, and in a percentage ratio $38.8 \%$.

In total for the oven installation, considering besides resistance of a tyre package, flexible cables and tubes of electrode keepers, we obtain $3.33 \mathrm{~m} \Omega$.

\subsection{The Furnace on the Graphitized Electrode}

For round three electrode half-closed furnaces we choose the graphitized electrodes with a diameter of $600 \mathrm{~mm}$ at working current of $40 \mathrm{kA}$. Admissible value of the currents density in the electrode is equal to $15 \mathrm{~A} / \mathrm{cm}^{2}$.
Proceeding from the chosen diameter of the electrode we calculate main characteristics of the furnace.

(1) Accepting from the Ref. [8] $\eta_{e l} \cdot \cos \phi=0.78$, we find the useful power of the Furnace $P_{u s}=8,400 \mathrm{~kW}$.

(2) Diameter of the bathtub at the level of coal blocks:

$D_{B}=5.1 \cdot d_{e l}=5.1 \times 600=3,060 \mathrm{~mm}$.

(3) Diameter of the bathtub above the coal blocks:

$d_{B}=5.3 \cdot d_{e l}=5.3 \times 600=3,180 \mathrm{~mm}$.

(4) Bathtub height:

$H_{B}=2.5 \cdot d_{e l}=2.5 \times 600=1,500 \mathrm{~mm}$.

(5) Height of the coal facing:

$$
H_{C}=0.65 \cdot d_{e l}=0.65 \times 600=390 \mathrm{~mm} .
$$

Both considered furnaces work at the oven transformer main data of which are given in Table 1.

We will determine power parameters of the considered furnaces.

For the furnace on the self-baking electrodes.

(1) Specific power on the surface of the bottom [9]:

$$
P_{S B}=\frac{4 \cdot P \cdot \eta_{\Im n}}{\pi \cdot d_{B}^{2}}=\frac{4 \cdot 9300 \cdot 0.88}{3.14 \cdot 4.4^{2}}=538 \mathrm{~kW} / \mathrm{m}^{2},
$$

where, $P=9,300 \mathrm{~kW}$ - the power consumed by the furnace from the network;

$\eta_{e l}=0.88$ - electrical efficiency of the furnace.

(2) Specific power in the bathtub volume:

$$
P_{V B}=\frac{P_{S B}}{H_{B}}=\frac{538}{1.99}=270 \mathrm{~kW} / \mathrm{m}^{3} .
$$

For the furnace on the graphitized electrodes.

(1) Specific power on the bottom surface:

$$
P_{S B}=\frac{4 \cdot P \cdot \eta_{э \jmath}}{\pi \cdot D_{B}^{2}}=\frac{4 \cdot 9300 \cdot 0.8}{3.14 \cdot 3.06^{2}}=1,012 \mathrm{~kW} / \mathrm{m}^{2} .
$$

(2) Specific power in volume of the bathtub:

$$
P_{V B}=\frac{P_{S B}}{H_{B}}=\frac{1,012}{1.5}=675 \mathrm{~kW} / \mathrm{m}^{3} .
$$


Table 1 Ratings of the oven transformer.

\begin{tabular}{|c|c|c|c|c|c|}
\hline \multirow{2}{*}{$\begin{array}{l}\text { Position of the } \\
\text { indicator }\end{array}$} & \multirow{2}{*}{ Rated power $(\mathrm{kV} \cdot \mathrm{A})$} & \multicolumn{2}{|c|}{$\begin{array}{l}\text { Side of high } \\
\text { tension }\end{array}$} & \multicolumn{2}{|r|}{$\begin{array}{c}\text { Side of low } \\
\text { tension }\end{array}$} \\
\hline & & $\mathrm{V}$ & A & V & A \\
\hline 1 & 11,085 & \multirow{14}{*}{10,500} & 610 & 160 & \multirow{14}{*}{40,000} \\
\hline 2 & 10,739 & & 590 & 155 & \\
\hline 3 & 10,392 & & 571 & 150 & \\
\hline 4 & 10,046 & & 552 & 145 & \\
\hline 5 & 9,699 & & 533 & 140 & \\
\hline 6 & 9,353 & & 514 & 135 & \\
\hline 7 & 9,007 & & 495 & 130 & \\
\hline 8 & 8,660 & & 476 & 125 & \\
\hline 9 & 8,314 & & 457 & 120 & \\
\hline 10 & 7,967 & & 438 & 115 & \\
\hline 11 & 7,621 & & 419 & 110 & \\
\hline 12 & 6,928 & & 381 & 100 & \\
\hline 13 & 6,235 & & 343 & 90 & \\
\hline 14 & 5,543 & & 305 & 80 & \\
\hline
\end{tabular}

From the analysis of power indicators of furnaces follows that despite of the high cost of the graphitized electrodes in comparison with the shelf-baking electrodes, power parameters are improved greatly. Besides, the natural power factor increases, melting time decreases and the most important is that the furnace becomes compact, that is convenient for service, building up of the graphitized electrodes is carried out for a small period of time and also the number of service personnel is reduced.

For the first time in practice we have carried out the original scheme of the short network with application of console electrode keepers for the graphitized electrodes.

Technical and economic indexes of the furnace installation are highly dependent on the major parameters of the furnace contour, i.e. on its active and reactive resistances [1,2].

The reduction in the inductive reactance of low-voltage circuit, which in the large furnaces is 5-7 times higher than the active one, is of high importance, and besides, it determines $\cos \phi$.

It is known that the effective inductance of two straight-line parallel conductors of equal length with the currents of the reverse directions is calculated by the formula:

$$
L=L_{11}+L_{22}-M_{12}-M_{21}=2\left(L_{11}-M\right)
$$

where,

$$
\begin{aligned}
& L_{11}=L_{22} \text {-self-inductances of the conductors; } \\
& M_{12}=M_{21}=M-\text { mutual inductances between }
\end{aligned}
$$
these conductors.

In the calculation of the factors $L$ and $M$, there is usually used the following formula:

$$
L(M)=2 l\left(\ln \frac{2 l}{d}-1\right) \cdot 10^{-9}[H]
$$

where, $l$-is a length of the conductor, $d$-linear dimension dependent on the cross-section shape and relative positions of the conductors.

When calculating $L, d$ is a root mean displacement of the area from itself, but when calculating $M, d$ is a distance between the sections of the conductors.

The aforementioned formulas show that the reduction in the reactive resistance of low-voltage circuit was achieved by the possible reduction in the length of the current-conducting wires, and by 
approaching conductors with the currents of the reverse directions, in other words, by bifilar arrangement of tires or cables.

One of radical ways to reduce inductance of low-voltages circuit consists in designing the current-conducting wire according to the scheme "a triangle on the electrodes".

On some industrial furnaces of different capacity, there has been implemented a three-bifilar scheme with the fourth arm moving simultaneously with the first one. However, this scheme has resulted in the substantial complication of furnace maintenance. In addition, the bifilar guide tubes are located on the different arms, in practice, as a rule, they are positioned at different levels, at the same time, during the period of smelting, the mutual induction effect varies frequently, as well as the value of reactive resistance.

Because of great difficulty in production and maintenance, we had to abandon this scheme. Therefore, the given paper proposes more perfect design of low-voltage circuit, the application of which allows for improving significantly furnace operating factors in all periods of smelting.

Fig. 1 illustrates a new schematic structural diagram of low-voltage circuit according to the scheme "a triangle on the electrodes" designed in a three-bifilar version, in which more complete symmetry is gained by means of the crosspieces forming a triangle directly at the electrode arms. As the crosspieces, there have been used special flexible, water-cooled cables, the length of which is determined from the distance between the electrodes and from the electrode travel. The crosspieces should facilitate the provision of the required displacement of the electrodes. The current-carrying tubes, which have different polarity and are isolated from one another, are located on the same arm that leads to further reduction in low-voltage circuit inductance, since all of the elements of a current lead that carrying the currents of different directions are positioned right next to each other. Here, the phase currents run through the conductors of low-voltage circuit, the difference between which forms the linear currents in the electrodes.

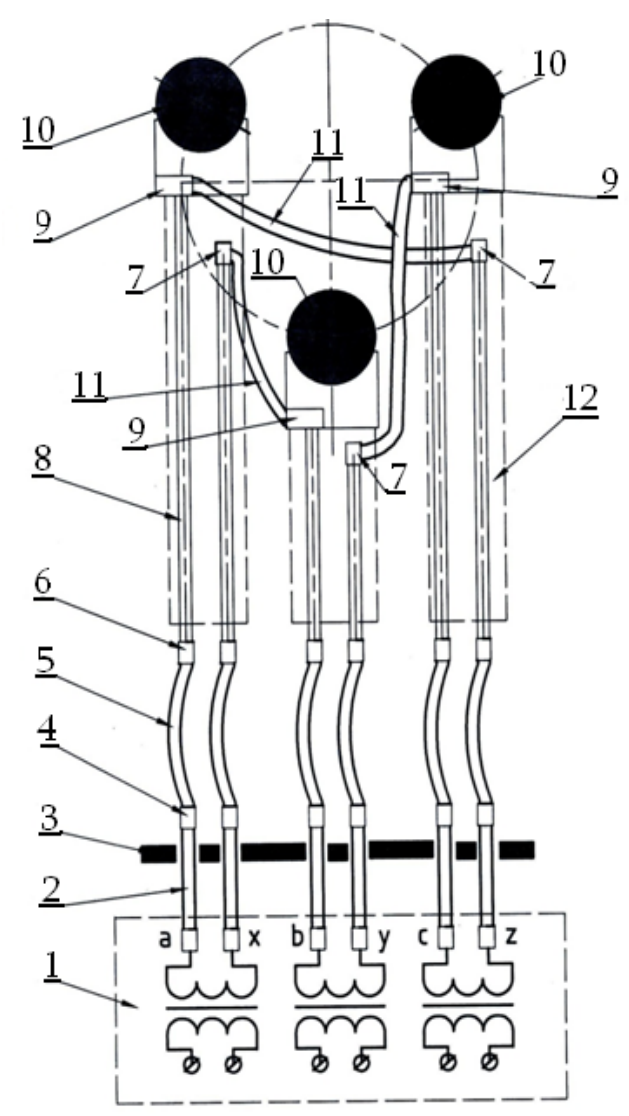

1-Transformer; 2-Busbar package; 3-Furnace sub-station wall void; 4-Stationary shoe; 5-Flexible cables; 6, 7-Traveling shoe; 8-Bus tubes 9-Contact-type current-conducting plate with the electrode arm body; 11-Crosspieces forming a triangle at the electrode arms; 12-Electrode arms.

Fig. 1 Low-voltage circuit according to the scheme "a triangle on the electrodes" designed in a three-bifilar version.

Table 2 The basic technical data of the electric furnace transformers.

\begin{tabular}{llllll}
\hline Rated power (MVA) $\begin{array}{l}\text { Primary voltage } \\
(\mathrm{kV})\end{array}$ & $\begin{array}{l}\text { Secondary voltage } \\
(\mathrm{V})\end{array}$ & $\begin{array}{l}\text { Secondary linear } \\
\text { current }(\mathrm{kA})\end{array}$ & $\begin{array}{l}\text { Secondary phase } \\
\text { current }(\mathrm{kA})\end{array}$ & $\begin{array}{l}\text { The number of } \\
\text { secondary voltage levels }\end{array}$ \\
\hline 5.0 & 10.00 & $137.6 \div 70$ & 21 & 12.1 & 9 \\
11.0 & 10.5 & $160 \div 80$ & 40 & 23.1 & 14 \\
\hline
\end{tabular}


Table 3 The basic design characteristic data of the secondary current-conducting wires for the furnaces with the power capacities of 5 and $11 \mathrm{MV} \cdot \mathrm{A}$.

\begin{tabular}{|c|c|c|c|c|c|c|c|c|c|}
\hline \multirow[b]{2}{*}{$\begin{array}{l}\text { Secondary } \\
\text { current } \\
(\mathrm{kA})\end{array}$} & \multicolumn{2}{|l|}{ Bus bar bridge } & \multicolumn{2}{|c|}{$\begin{array}{l}\text { Water-cooled flexible } \\
\text { cables }\end{array}$} & \multicolumn{3}{|l|}{ Bus tubes } & \multicolumn{2}{|c|}{ Graphite electrodes } \\
\hline & $\begin{array}{l}\text { Busbar } \\
\text { cross-section and } \\
\text { quantity for a } \\
\text { pole-phase }(\mathrm{mm})\end{array}$ & $\begin{array}{l}\text { Current } \\
\text { density } \\
\left(\mathrm{A} / \mathrm{mm}^{2}\right)\end{array}$ & $\begin{array}{l}\text { Cross-section } \\
\text { and quantity, for } \\
\text { a pole-phase } \\
(\mathrm{mm})\end{array}$ & $\begin{array}{l}\text { Current } \\
\text { density } \\
\left(\mathrm{A} / \mathrm{mm}^{2}\right)\end{array}$ & $\begin{array}{l}\text { Diameter } \\
(\mathrm{mm})\end{array}$ & $\begin{array}{l}\text { The } \\
\text { quantity of } \\
\text { tubes for a } \\
\text { pole-phase }\end{array}$ & $\begin{array}{l}\text { Current } \\
\text { density } \\
\left(\mathrm{A} / \mathrm{mm}^{2}\right)\end{array}$ & $\begin{array}{l}\text { Diameter } \\
(\mathrm{mm})\end{array}$ & $\begin{array}{l}\text { Current } \\
\text { density } \\
\left(\mathrm{A} / \mathrm{mm}^{2}\right)\end{array}$ \\
\hline 20,000 & $2(250 \times 12)$ & 1.9 & $1,000 \times 4$ & 2.9 & $80 / 40$ & 1 & 3.0 & 400 & 15.9 \\
\hline 40,000 & $4(400 \times 12)$ & 1.22 & $1,000 \times 8$ & 2.89 & $100 / 60$ & 1 & 4.6 & 600 & 14.1 \\
\hline
\end{tabular}

The arrangement of the arms at different levels for the proposed scheme has no effect on mutual induction of semi-phases, since the reactive resistance total value of a secondary current lead does not change.

On one of the ferroalloy furnaces with a power capacity of $11 \mathrm{MV} \cdot \mathrm{A}$ (Argveta plant, "GiTim Group", Georgia), instead of a typical scheme of low-voltage circuit (a triangle on the stationary shoes), we have proposed and implemented the scheme of the aforementioned design of a secondary current, which we have pretested on a ferroalloy furnace with a power capacity of $5 \mathrm{MV} \cdot \mathrm{A}[3,10]$.

The above discussed furnaces are packaged complete with the electric furnace transformers, the characteristics of which are given in Table 2.

Table 3 presents the basic design characteristics of the secondary current-conducting wires for the furnaces with the power capacities of 5 and $11 \mathrm{MV} \cdot \mathrm{A}$.

In the scheme, the conductor sections are calculated by the maximum permitted current density. The bus bar packages were designed exclusively on a laminated form. For the flexible current-conducting wires, there have been used the copper water-cooled wires, but for the bus tubes - the water-cooled copper pipes.

\section{Conclusions}

(1) The comparative analysis of the ore reduction furnaces of equal power shows that despite of high cost of the graphitized electrodes in comparison with self-caking electrodes, power parameters improve greatly, the natural power factor increases, melting time decreases, the furnace becomes compact and convenient for service, building up of the graphitized electrodes is carried out for a small period of time, and also the number of service personnel is reduced.

(2) Application of the original scheme of the short network on the console electrodes reduces both the active and reactance of the oven installation and increases power factor.

(3) The application of the proposed scheme allows for reducing the reactive resistance by 2.5-3 times, and the active resistance-by $15-20 \%$, as well as for shortening the heat, reducing specific energy consumption and increasing the installation power factor.

\section{References}

[1] Kldiashvili, V. I., Kashakashvili, G. B., and Mebonia, S. A. 2001. "Ore-Reducing Shaft Furnace for Preparing and Smelting the Lumped Charging Materials." Metallurgist (11): 47-8.

[2] Kldiashvili, V. I., Kashakashvili, G. B., Mebonia, S. A., and Lomtatidze, G. A. 2006. "Universal Closed Arc for Receiving Steel Directly from Briquettes of Iron Ore Mono Charge." Metallurgist (11): 53-4.

[3] Kldiashvili, V. I., Kashakashvili, G. B., and Mebonia, S. A. 2006. "Ore Reduction Arc Furnaces for Making of Alloy." Metallurgist (8): 53-4.

[4] Kldiashvili, V. I., Tsirdava, M. O., Melkadze, D. G., and Mebonia, S. A. 2009. "Ferro Melted Refined Furnaces." Engineering Magazine (3): 59-62.

[5] Kldiashvili, V. I., Simongulashvili, Z. A., Tsirdava, M. O., Melkadze, D. G., and Mebonia, S. A. 2009. "The Ore Reduction Arc Furnace for Production of Silico-Manganese." Engineering Magazine (3): 62-6.

[6] Babat, G. I., Dershvarts, G. V., Svenchansky, A. D., and Smelyansky, M. A. 1948. "Energetic Industry Furnaces." Gosenergoizdat, 258-62. 
[7] Nikolsky, L. E. 1971. "Plants of Arc Heating and Their Parameters." Energy, 269.

[8] Dantsis, I. B., and Zhilov, G. M. 1987. Short Networks and Electric Parameters of Arc Electric Furnaces. Moscow: Metallurgy, 126-37.
[9] Strunsky, B. M. 1972. Ore Thermal Melting Furnaces. Moscow: Metallurgy.

[10] Kldiashvili, V. I., Kashakashvili, G. B., and Mebonia, S. A. 2008. "Rational Scheme of Electro-Supply of Ore Reduction Furnaces.” Metallurgist (8): 44. 